\title{
Alcohol and Alcoholism
}

\section{Overture to the alcohol debate}

\author{
RICHARD SMITH
}

When World Medicine asked six well-known doctors how they should spend their last minutes if the nuclear bombs were dropping four of them in the few sentences allotted mentioned drinking alcohol. ${ }^{1}$ Though the feature was hardly serious, it is one illustration of how important alcohol is today. In the last 20 years alcohol consumption in Britain has roughly doubled (figure) and the same trend has been seen in most Western countries." From 1960 to 1972 world production of beer increased by $68 \%$, of spirits by $61 \%$, and of wine by $19 \% \%^{3}$ The drink industry two years ago was predicting that this trend would continue: whisky consumption was expected to rise between 1978 and 1991 by $6-32 \%$ and beer consumption by $21 \%$ between 1977 and 1988.* Associated with the increase in consumption has been an increase in the many forms of individual and social damage associated with alcohol. ${ }^{2}$ Also rising is the concern of those most closely associated with alcohol problems, and a bandwagon to reduce the harm is rolling.

Alcohol problems have moved on to the agendas of many international, professional, and governmental committees. In the last four years the World Health Organisation Expert Committee, ${ }^{4}$ the Department of Health and Social Security Advisory Committee on Alcoholism, ${ }^{5}$ the House of Commons Expenditure Committee, ${ }^{6}$ the Royal College of Psychiatrists, ${ }^{2}$ and, most recently, the Central Policy Review Staff (the Government "think tank")? have considered the problem. All have reached similar conclusions and have recommended that the Government at the very least should not allow alcohol consumption to rise any further. No radical action has yet been

*In fact, in the second quarter of 1981 beer production in Britain was down by $7 \cdot 8 \%$ compared with the same quarter for 1980 . Wine consumption increased by about $11 \%$ in 1980, however, and spirit consumption rose by about $5 \%$. The Brewers' Society thinks that beer production has fallen because of the recession, continuing inflation, tax increases, and the poor weather early this summer. It does not think that the fall will continue, but prediction is a difficult art in such uncertain times.

British Medical Journal, London WC1H 9JR RICHARD SMITH, BSC, MB, assistant editor

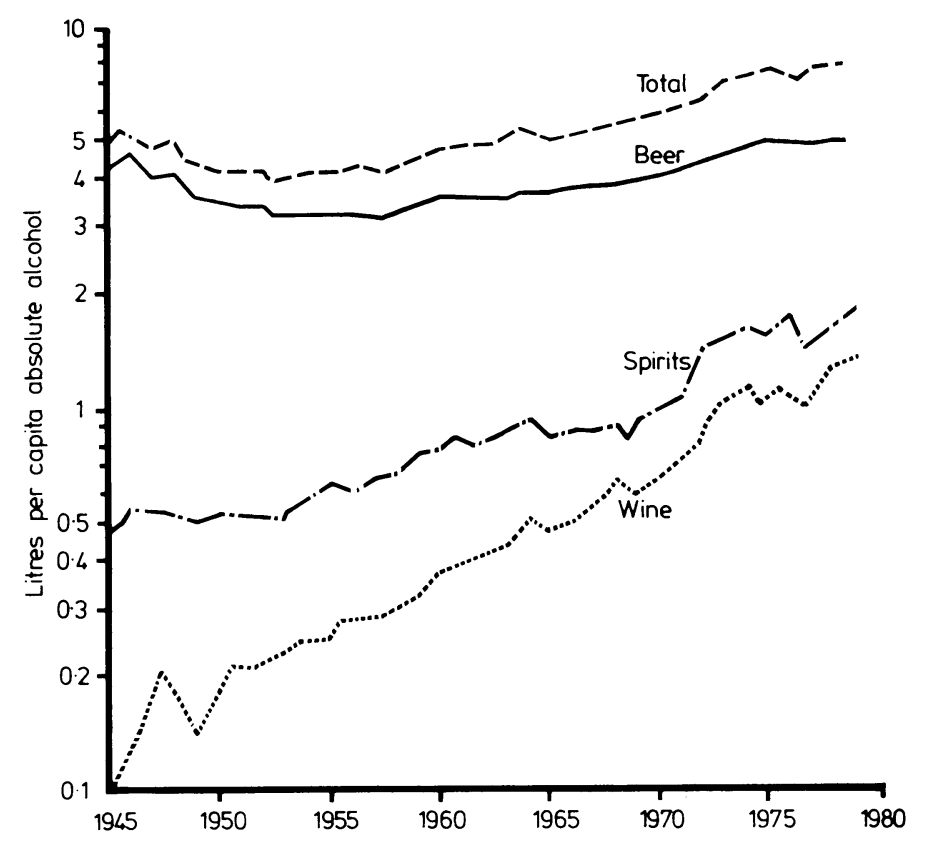

Beer, spirit, wine, and total alcohol consumption in Britain from 1945-79 (source: Office of Health Economics ${ }^{18}$ ).

taken, however: indeed the think tank report was suppressed. But if alcohol consumption and harm continue to rise then the Government may eventually be obliged to act.

These committees have begun to consider alcohol problems not only because alcohol-related harm is increasing but also because our understanding of alcohol problems has undergone a revolution in the last 20 years. In the years after the second world war consumption and damage were both comparatively low, and in the heady days of the first antibiotics and the appearance of the National Health Service few health workers or scientists in Britain were much interested in alcohol problems. 
Alcoholism was assumed to be a disease that affected only a small proportion of the population, who were peculiar in some genetic, biochemical, or psychological way. This idea was acceptable to both alcoholics, who were better off being thought sick rather than bad, and the drink trade, who could push alcohol sales confident that most people could not be harmed. No evidence was available to support this concept of alcoholismit was simply assumed to be so.

\section{Alcohol is what matters}

Now that data have become available from around the world on how individuals and societies use alcohol these old ideas have changed. Separating alcoholics from non-alcoholics has proved to be impossible. The drinking pattern of many groups has been surveyed, and graphs showing how much people drink are always unimodal: there is no discrete population of individuals who drink more than everybody else. ${ }^{8}$ Furthermore, longitudinal studies have shown that individuals can begin to drink more and move into a phase where they have symptoms associated with alcohol dependence, and, conversely, if they begin to drink less they can move out of this phase. ${ }^{9}$ Certainly some people and some groups-for example, women-are more vulnerable than others to damage by alcohol but it seems as if everybody, given sufficient alcohol, is capable of becoming dependent.

Another reason for health workers, researchers, and governments to concentrate on alcohol rather than alcoholism is the great range of alcohol-associated damage. As well as the physical and mental damage associated with long-term alcohol abuse there is all the damage associated with intoxication. Many of the people killed in accidents on the road, in the home, and at work are not alcohol addicts-they may be only occasional drinkers. Alcohol is also associated with suicide, crime, violence, family breakdown, self-poisoning, and various cancers: alcohol misuse is a social disease with medical complications. Few of these problems result directly from alcohol, however, and a society that consumed less alcohol would not necessarily have less suicide, crime, or violence.

But it does seem that most of the various measures of alcohol damage do correlate with a society's consumption of alcohol. Indeed, the French demographer Ledermann was so impressed by survey data showing the relationships between amount of alcohol consumed, the number of heavy drinkers, and the degree of alcohol-associated damage in various populations that he developed a mathematical model to explain the relationships. ${ }^{10}$ His mathematics have since been criticised, ${ }^{811} 12$ and patterns of alcohol damage within groups found to depend on more than the total amount consumed. ${ }^{13}$ Nevertheless, virtually everybody who studies alcohol problems is agreed that the more alcohol a group consumes the more alcohol-associated damage will result. This important idea (the details of which will be discussed in the next article), which has probably changed thinking on alcohol problems more than any other, has led to proposals that the answer to alcohol problems lies less with health and social workers and more with politicians. ${ }^{14}$

\section{Costs and benefits of alcohol}

In these days of financial stringency, when an issue becomes a political one a cost-benefit analysis is called for. The aim seems to be to convert every plus and minus to one measuremoney-and then hope that the best policy will become clear. This is a difficult exercise for alcohol because the forms of damage are so diverse, the data are weak, and both costs and particularly benefits are hard to measure in money terms.

Cost-benefit analyses of alcohol tend to concentrate on costs. Most people in Britain drink (as opposed, for example, to Ireland, the United States, and Scandinavia, where about $20-40 \%$ of the population does not drink) and presumably are aware of the benefits. Those people who drink a little live longer than those who do not drink at all. ${ }^{15} 16$ Whether this means there is benefit to be had from moderate drinking or whether those people who do not drink at all are odd in some way is not entirely clear, but some researchers believe that moderate drinking protects against heart disease. ${ }^{1617}$

Benefits to individuals may be hard to define, but hard figures can be put on the benefits to the British economy. In 1979 terms Britain spent $£ 9000 \mathrm{~m}$ on alcohol $-8 \%$ of all consumer outlay. ${ }^{1 \times}$ The drink trade provides about 700000 jobs, the Government raises $\$ 3500 \mathrm{~m}$ in revenue from alcohol, and a balance of trade surplus of $f 500 \mathrm{~m}$ results from alcohol. ${ }^{18} \mathrm{With}$ alcohol providing so much revenue, jobs, and exports, the Government is understandably unwilling to take any political action to limit consumption.

Yet the costs of alcohol are not only a formidable amount of suffering, but also very real economic ones incurred through treatment programmes, social services, lost productivity, damage due to accidents, and policing and legal costs. (These activities too employ many people, a cynic might observe.) A DHSS study group added up these costs-necessarily making some bold guesses in the process - and came up with a total annual cost for $1977-78$ of $£ 650 \mathrm{~m} \cdot{ }^{19}$ And this, as the authors explain and the Office of Health Economics agrees, ${ }^{18}$ is a conservative estimate that does not attempt to put a figure on suffering. An American Government estimate of the community cost of alcohol was $\$ 43$ billion in $1975^{20}$-about $£ 25000-£ 30000 \mathrm{~m}$ in 1981 terms. $^{18}$ An Institute of Medicine study group has suggested that even these figures were an underestimate, and it thinks a more likely figure for 1978 was $\$ 60$ billion. $^{2}$

\section{Human costs}

Whatever the exact economic cost, the human costs of alcohol abuse are enormous. Estimating the number of people dependent on alcohol is difficult: the two main problems are defining what constitutes dependence and discovering how much people drink. One San Francisco study showed that a strict definition of alcoholism produced a prevalence rate of three per 1000, while criteria that included any drinking problem past or present gave a prevalence rate of 272 per $1000 .{ }^{21}$ Clearly, where the epidemiologist draws his line makes a big difference. Generalising from figures obtained in one group in one area to produce figures as to how many alcoholics or problem drinkers there are in Britain is also unreliable. Consequently, estimates of the number of alcohol-dependent people in England and Wales vary from 70000 to 240000 and those for the number of problem drinkers from 500000 to $1300000 .^{18}$

Adding up deaths caused by alcohol is also difficult. Alcoho plays a prominent part not only in deaths from cirrhosis, accidents, and suicide but also in some deaths from cardiovascular, infective, respiratory, and gastrointestinal conditions. Alcohol abuse probably also contributes to the perinatal mortality rate and the incidence of malformations. ${ }^{22}$ The Office of Health Economics estimates that alcohol causes about 510000 premature deaths annually in Britain. ${ }^{18}$

But unlike cigarette smoking, alcohol abuse contributes much more to morbidity than mortality. To know the number of hangovers a year in Britain and how many people work below capacity because of alcohol problems would be fascinating, but these figures are not available. The DHSS study group, however, estimated that sickness absences from work due to alcohol cost about $£ 200 \mathrm{~m}$ annually in $1977-78 .{ }^{18}$ About 70000 individuals were found guilty of drunkenness on roughly 110000 occasions in 1980. ${ }^{17}$ Finally, alcohol misuse is associated with crime, mental illness, and violence in ways that are hard to explain or measure.

So what kind of response can be made to this tide of problems, all of which have been increasing for the last three decades? The traditional response has been to try to help the individuals damaged by alcohol rather than prevent the problem at source (although precedents exist of the Government acting to reduce 
alcohol consumption-for example, in 1751, 1828, and 1914). But there are serious problems with this treatment response.

Firstly, a considerable gap seems to exist between the number of people in the community who have alcohol problems and the number who receive any treatment. One study in south London found a prevalence rate of $3 \cdot 5^{\circ}$ " of people with alcohol problems, while in that year only $0 \cdot 16^{\circ}$ " had received any treatment for alcohol problems. ${ }^{23}$ This difference is due in part to one figure being a prevalence and the other an incidence; also not all of the problems concerned in the prevalence study would need or deserve treatment. Nevertheless, many people who have problems do not receive any treatment. Studies in general practice have supported this finding." problem drinkers" raise serious logistic problems for the treatment agencies. As it is the agencies in Britain are overstretched and underfunded. ${ }^{26}$ If they were suddenly asked to treat thousands more patients they would not be able to cope -as they could not when a Health Education Council campaign in north-east England encouraged people with drinking problems to come forward for treatment. Many came forward and swamped the available services.

Secondly, doubts exist whether treatment makes much difference to outcome. ${ }^{27}$ Martin Plant, somebody who has spent a long time researching the use and misuse of alcohol, said to me: "Whatever kind of drug addiction you consider treatment doesn't seem to matter much-whatever the treatment a third get better, a third stay the same, and a third get worse." Edwards's well-known study presents some support for this generalisation ${ }^{2 x}$ : 50 alcohol-dependent men treated intensively with all the facilities of an alcohol unit did just as well (or badly) after one year as a control group simply given a solemn warning. One of the main conclusions from a large review of outcome studies was that it was easier for incorrect treatments to retard recovery than for proper ones to hasten it. ${ }^{29}$

In some ways the results of these studies are encouraging. They might be taken as meaning that a general practitioner could do a great deal to help patients with alcohol problems in a short time and with limited resources. Russell et al have shown that general practitioners effectively help patients stop smoking, ${ }^{30}$ and perhaps a similar study for alcohol patterns would give equally encouraging results. At the moment general practitioners seem to be pessimistic about the results of treating people with alcohol problems. ${ }^{31}$ This pessimism about outcome, rather than because general practitioners are not detecting patients with alcohol problems, may be the reason why general practice is making so little impact on the current tide of alcohol problems.

Another way of helping problem drinkers is at work, and this has become popular in the United States. ${ }^{32}$ The advantages are that problems can be detected at an early stage and that both employees and employers are strongly motivated to co-operate when livelihoods are at stake. Some impressive treatment results have been seen in some industries in the United States, ${ }^{32}$ but British companies have been slow to develop alcohol programmes, partly because of traditional British inertia and partly because unions have been worried that the programmes may deteriorate into devices for sacking employees with drink problems. The Government, however, believes that work-based treatment programmes will be important and gave a considerable boost to the recent booklet produced jointly by the Health and Safety Executive, Health Departments, and Department of Employment, The Problem Drinker at Work. ${ }^{33}$ How much this is real committment and how much just a desire to be seen to be doing something about alcohol problems will become clearer with time.

Most of these treatment programmes are aimed at drinkers who have not yet damaged themselves irreversibly. The Health Service is still left to treat patients with severe physical disease and trauma resulting from alcohol abuse, and the social services are left to pick up the pieces of families, marriages, and lives wrecked by drink. Some of these disillusioned and overworked people are the ones who argue most strongly for a comprehensive programme of prevention.

\section{Prevention predictably better than cure}

Education about alcohol problems is the least painful form of prevention, and yet there is little evidence that it can lessen morbidity or mortality. Finding an example of an educational campaign that has worked is hard. But then any one campaign cannot be expected to have much effect; few campaigns have been well evaluated; and most of the campaigns waged so far in Britain have started with limited resources and confused aims. Participants have disagreed over whom the campaigns should aim at and what message they should deliver.

Dissatisfaction with treatment and education programmes has led many to suggest political strategies for prevention. Those suggested include raising the real price of alcohol, banning advertising, changing the licensing laws, reducing the number of outlets for alcohol, and increasing the penalties for drunken driving and similar offences. Like most political strategies these threaten vested interests and promote fierce controversy about both the morality and the effectiveness of such moves. A Sunday Times ${ }^{34}$ poll last December showed that although most of the population would favour tougher sentences for drunken driving they would also oppose large increases in the price of alcohol.

\section{Alcohol research}

One last theme I want to develop in this overture to a series of articles on alcohol is that alcohol research is underfunded. The changes in thinking about alcohol problems have resulted from what in many ways has been only the most preliminary research. Reviews of alcohol studies-particularly epidemiological studies, which have produced rich rewards-always mention the inadequacy of the data. Britain and even the United States have relatively few alcohol researchers, and the Institute of Medicine in the US has produced figures (table) showing how little is spent on alcohol research compared with the costs incurred by alcohol abuse. Similar figures do not exist for

Amount spend on research into various problems in relation to the economic cost of the problem in the United States

\begin{tabular}{|c|c|c|c|c|}
\hline Problem & & $\begin{array}{c}\text { Estimate of } \\
\text { research } \\
\text { expenditure } \\
\text { in } 1978 \\
(\$ \mathrm{~m})\end{array}$ & $\begin{array}{l}\text { Estimate of } \\
\text { economic cost } \\
\text { in } 1975 \\
(\$ 000 \mathrm{~m})\end{array}$ & $\begin{array}{l}\text { Research dollars } \\
\text { per thousand } \\
\text { dollars of cost }\end{array}$ \\
\hline $\begin{array}{l}\text { Alcohol abuse } \\
\text { Cancer } \quad \ldots\end{array}$ & $\begin{array}{l}\ldots \\
\cdots \\
\cdots\end{array}$ & $\begin{array}{r}16 \\
627 \\
284 \\
69\end{array}$ & $\begin{array}{l}43 \\
19 \\
46 \\
19\end{array}$ & $\begin{array}{c}0 \cdot 4 \\
30 \\
6 \\
4\end{array}$ \\
\hline
\end{tabular}

Source: Institute of Medicine. ${ }^{21}$

Britain, but there is every reason to suppose that they would show a similar pattern. More money does not, of course, automatically mean more effective research, but money is essential and these American figures provide a strong argument for increasing financial support to alcohol research.

This is the first in a series of articles on alcohol.

\section{References}

1 Anonymous. Booze, Bach, and the big bang. World Medicine 1980;13 December :89.

2 Special Committee of the Royal College of Psychiatrists. Alcohol and Alcoholism. London: Tavistock Publications, 1979.

${ }^{3}$ Finnish Foundation for Alcohol Studies and World Health Organisation Regional Office for Europe. International statistics on alcohol beverages: production, trade and consumption 1950-1972. Helsinki: Finnish Foundation for Alcohol Studies, 1977. 
4 World Health Organisation Expert Committee. Problems related to alcohol consumption. Geneva: WHO, 1979.

${ }^{5}$ Department of Health and Social Security Advisory Committee on Alcoholism. Report on prevention. London: HMSO, 1978.

${ }^{6}$ House of Commons Expenditure Committee. Report on preventive medicine. London: HMSO, 1977.

7 Dean M. Can the Government put Britain on the wagon? Guardian 1981; 18 February:9.

${ }^{8}$ de Lint L. The frequency distribution of alcohol consumption: an overview. In: Davies DL, ed. The Ledermann curve. London: Alcohol Education Centre, 1977.

9 Saunders WM, Kershaw PW. Spontaneous remission from alcoholisma community study. Br $\mathcal{F}$ Addict 1979;74:251-65.

${ }^{10}$ Ledermann S. Alcool, alcoolisme, alcoolisation. Paris: Presses Universitaires de France, 1956.

11 Miller EH, Agnew N. The Ledermann model of alcohol consumption. Quarterly Fournal of Studies on Alcohol $1974 ; 35: 877-98$.

12 Duffy J. Estimating the proportion of heavy drinkers. In: Davies DL, ed. The Ledermann curve. London: Alcohol Education Centre, 1977.

13 Plant MA, Pirie F. Self-reported alcohol consumption and alcohol related problems: a study in four Scottish towns. Social Psychiatry 1979;14 65-73.

14 Kendell RE. Alcoholism: a medical or a political problem ? $\mathrm{Br}$ Med $\mathcal{f}$ $1979 ; \mathrm{i}: 367-71$.

15 Marmot MG, Rose G, Shipley MJ, Thomas BJ. Alcohol and mortality: a U-shaped curve. Lancet $1981 ; \mathrm{i}: 580-3$.

16 Klatsky AL, Friedman MD, Siegelaub MS. Alcohol and mortality: a 10-year Kaiser-Permanente experience. Ann Intern Med 1981 ;95:139-45.

17 Kozararevic DJ, McGee D, Vojvodic N, et al. Frequency of alcohol consumption and morbidity and mortality: the Yugoslavia cardiovascular disease study. Lancet 1980;i:613-6.

18 Office of Health Economics. Alcohol: reducing the harm. London: OHE, 1981.

19 Holtermann S, Burchell A. The costs of alcohol abuse. Department of Health and Social Security, 1981.

${ }^{20}$ Berry RE, Boland JP, Smart CN, Kanak JR. The economic costs of alcohol abuse-1975. Washington: National Institute on Alcohol Abuse and Alcoholism, 1977.

21 Institute of Medicine. Alcoholism and related problems: opportunities for research. Washington: National Academy of Sciences, 1980.

2 Rosett HL. The effects of alcohol on the fetus and offspring. In: Kalant OJ, ed. Alcohol and drug problems in women. New York and London: Plenum Press, 1980.

23 Clarke W. Operational definition of drinking problems and associated prevalence rates. Quarterly Fournal of Studies on Alcohol 1966;27:648-68.

2 Cartwright AKJ, Shaw SJ, Spratley TA. Designing a comprehensive community response to problems of alcohol abuse. London: Department of Health and Social Security, 1975

25 Wilkins RH. The hidden alcoholic in general practice. London: Elek Science, 1974

26 Federation of Alcoholic Rehabilitation Establishments Working Party a the House of Commons. Community Services for Alcoholics. London FARE, 1979.

27 Clare AW. How good is treatment? In: Edwards G, Grant M, eds. Alcoholism: new knowledge and new responses. London: Croom $\mathrm{Helm}$ 1977

${ }^{28}$ Edwards G, Orford J. Alcoholism: a controlled trial of treatment and advice. F Stud Alcohol 1977;38:1004-31.

29 Emrick CD. A review of psychologically orientated treatment of alcoholism. II. The relative effectiveness of treatment versus no treatment. $\mathcal{F}$ Stud Alcohol $1975 ; 36: 88-109$.

${ }^{30}$ Russell MAH, Wilson C, Taylor C, Baker CD. Effect of general practitioners' advice against smoking. $B r \operatorname{Med} \mathcal{F} 1979$;ii:231-5.

${ }^{31}$ Rathod NH. Perception of alcoholism. In: Madden JS, Walker R, Kenyon WH, eds. Aspects of alcohol and drug dependence. London: Pitman Medical, 1980.

32 Hore BD, Plant MA, eds. Alcohol problems in employment. London: Croom Helm, 1981.

${ }^{33}$ Health and Safety Executive, the Health Departments, and the Department of Employment. The problem drinker at work. London: HMSO, 1981.

${ }^{34}$ Lipsey D. Random B-tests backed. Sunday Times 1980;28 December:1

\title{
Clinical Topics
}

\section{Asthma-expiratory dyspnoea?}

\author{
M J MORRIS
}

Recent work suggesting that expiration is passive even in severe airflow obstruction ${ }^{12}$ led us to question the generally held belief among doctors that expiration is more difficult for the asthmatic patient than is inspiration. To pursue this, we asked 119 asthmatic patients whether they found inspiration or expiration more difficult during an asthmatic attack (questionnaire I (fig 1)). We then asked 106 doctors to answer questionnaire II (fig 2) to determine what most doctors thought patients felt during an attack of asthma.

\section{Methods}

Patients attending an adult asthma clinic were handed questionnaire I (fig 1) and asked to answer it while they were in the clinic. Questionnaires were mailed to 30 asthmatic children (between 12 and 17 years) on the health visitor's list, and 23 returned the completed questionnaire. Questionnaire II was sent to each of 106 physicians, these being all the medical consultants and post-registration junior physicians in the Radcliffe Infirmary, Churchill, and John Radcliffe Hospitals, Oxford. Seventy-two questionnaires were completed and returned.

Department of Chest Diseases, Churchill Hospital, Oxford OX3 7LJ M J MORRIS, MD, medical assistant

\section{Results}

Only 22 patients (19\%) found expiration more difficult than inspiration during an asthmatic attack (table I). On the other hand, 56 doctors $(78 \%$ ) expected that asthmatic patients would find expiration more difficult (table II). Analysis of the doctors' reasons for thinking this showed that $66 \%$ of them did not base this belief on a history taken from their patients or their own experience of an asthmatic attack, but on their understanding of the physiology of airflow obstruction backed up by the appearance of the patient (table II, reasons 3, 4, and 5). Four doctors chose breathing out for reasons 4 or 5 or both (table II), but added handwritten reservations on their questionnaire forms such as "Some patients say breathing in."

\section{Discussion}

The pronounced discrepancy between the answers received from patients and doctors is disquieting. A limited historical review of medical textbooks shows that the idea of expiration being more difficult than inspiration was probably first introduced in the 1920s and has gradually been discarded since 1970 . In Osler's first edition $1892^{3}$ the "asthma fit" is described as follows: ". . . the patient is aroused with a distressing sense of want of breath and a feeling of great oppression in the chest. Soon the respiratory efforts become violent, all the accessory muscles are brought into play, and in a few minutes the patient 